\title{
Solubility of Polar and Non-Polar Aromatic Molecules in Subcritical Water: The Role of the Dielectric Constant
}

\author{
Supporting Information
}

\begin{abstract}
Nuno Galamba ${ }^{\mathrm{a}, *}$, Alexandre Paiva ${ }^{\mathrm{b}}$, Susana Barreiros ${ }^{\mathrm{b}}$, Pedro Simões $^{\mathrm{b}}$
${ }^{\text {a }}$ Centre of Chemistry and Biochemistry and Biosystems and Integrative Sciences Institute, Faculty of Sciences of the University of Lisbon, C8, Campo Grande, 1749-016 Lisbon, Portugal.

${ }^{\mathrm{b}}$ LAQV-REQUIMTE, Departamento de Química, Faculdade de Ciências e Tecnologia, Universidade Nova de Lisboa, 2829-516 Caparica, Portugal
\end{abstract}

*Corresponding author. Electronic mail: njgalamba@fc.ul.pt 


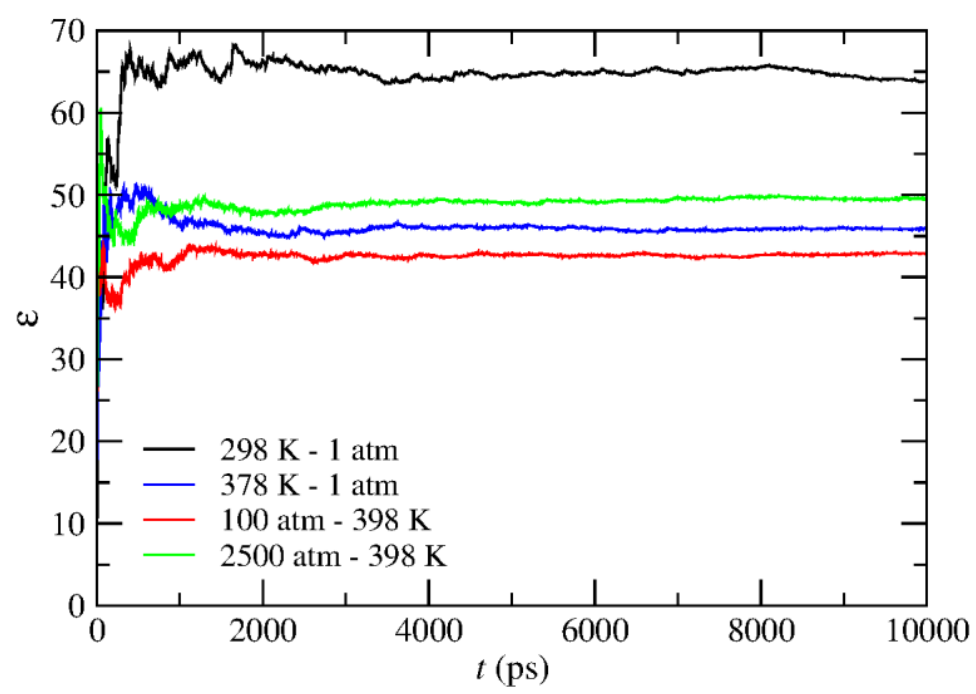

Figure 1-SI - Dielectric constant as a function of time as calculated through eq. (10) for TIP4P-Ew water at different temperatures and pressures, showing the convergence of the dielectric constant within $\leq 4 \mathrm{~ns}$ for different state points.
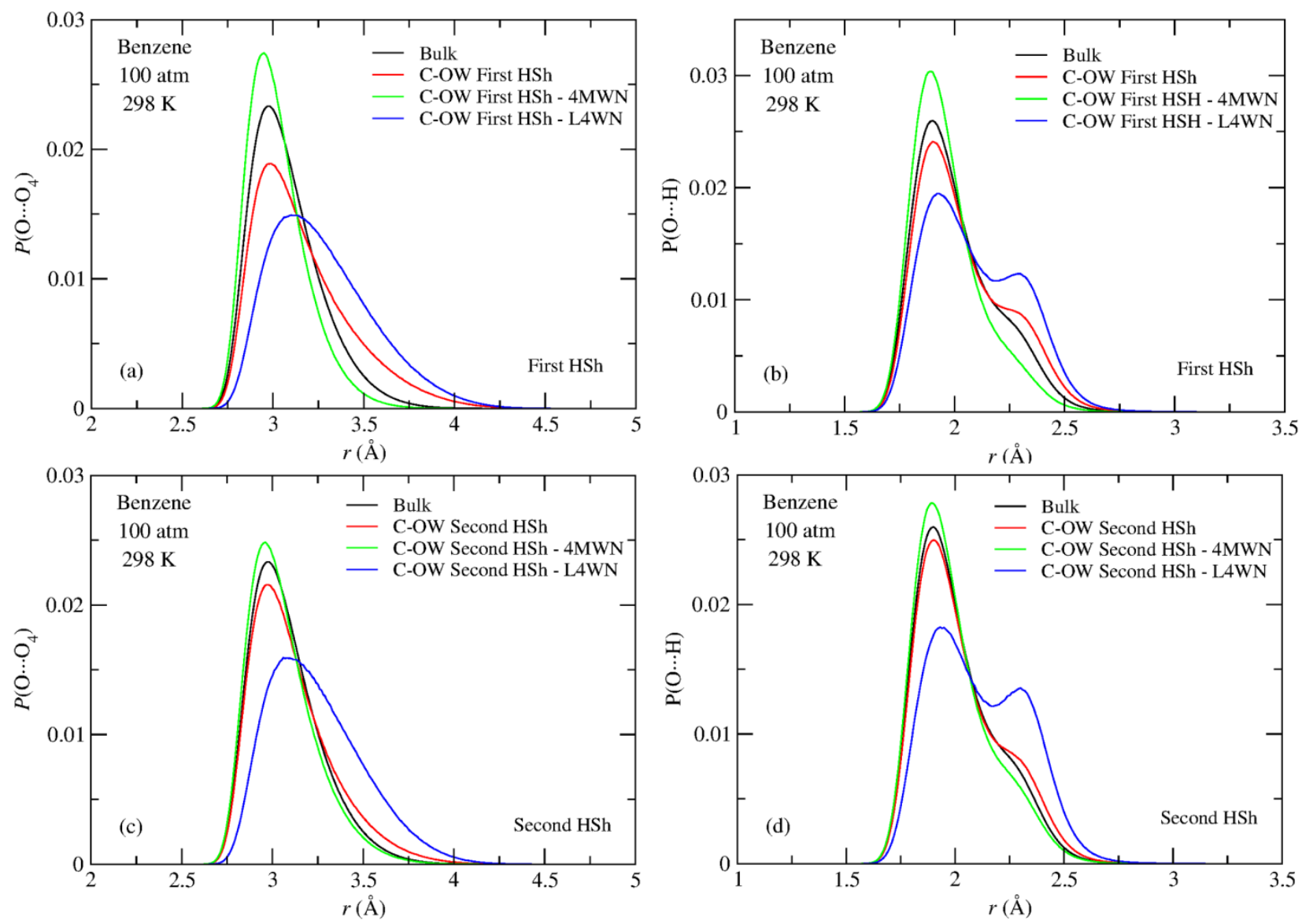

Figure 2-SI - $P\left(\mathrm{O} \cdots \mathrm{O}_{4}\right)$ and $P(\mathrm{O} \cdots \mathrm{H})$ distributions in a benzene aqueous solution at $298 \mathrm{~K}$ and $100 \mathrm{~atm}$. (a) and (c): $P\left(\mathrm{O} \cdots \mathrm{O}_{4}\right)$ distribution of the distance of an $\mathrm{O}$ atom to the fourth nearest $\mathrm{O}$ atom, for bulk water and for water in the first (F-HSh) and second (S-HSh) hydration shells of the $\mathrm{C}$ atoms of benzene; (b) and (d): $P(\mathrm{O} \cdots \mathrm{H})$ distribution of the distance of each $\mathrm{O}$ atom to the nearest two $\mathrm{H}$ atoms of neighbor water molecules for bulk water and for water in the F-HSh and S-HSh of the $\mathrm{C}$ atoms of benzene. The boundaries of the COW F-HSh and S-HSh are, respectively, $r<4.2 \AA$ and $4.2 \AA<r<5.4 \AA$; see Fig. 5-SI(b). 


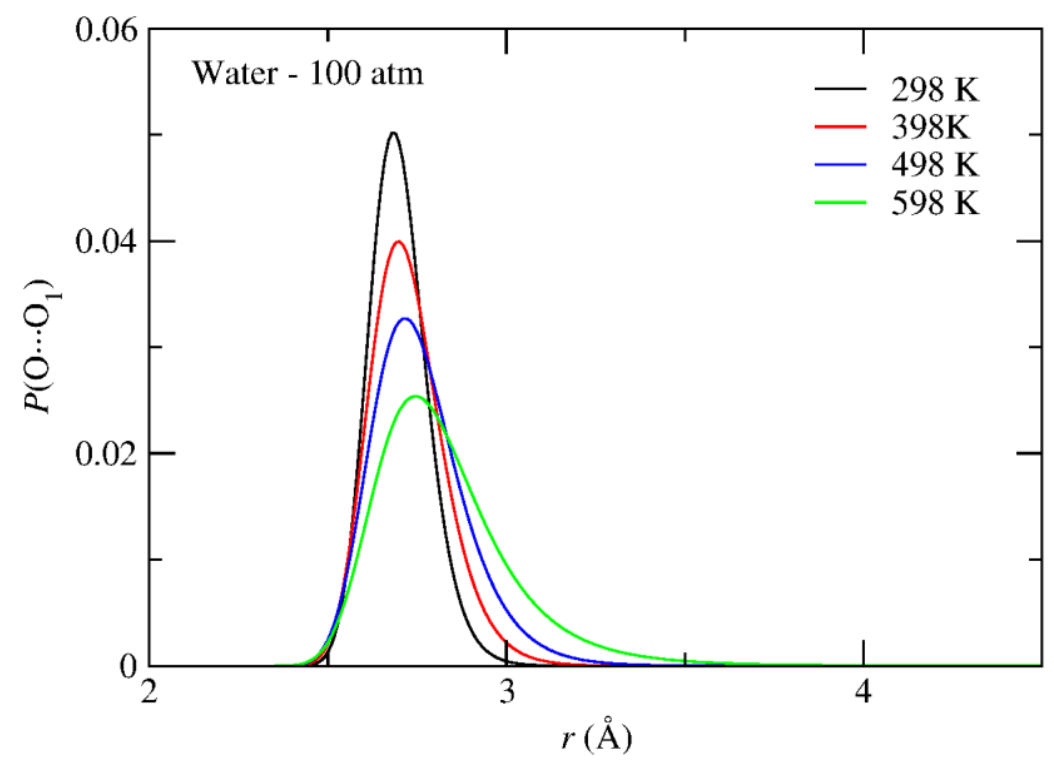

Figure 3-SI - $P\left(\mathrm{O} \cdots \mathrm{O}_{1}\right)$ distributions in bulk water at $100 \mathrm{~atm}$ and temperatures between $298 \mathrm{~K}$ and $598 \mathrm{~K}$.

The average distance increases from $2.7 \AA$ to $2.8 \AA$, from $298 \mathrm{~K}$ to $598 \mathrm{~K} ; \Delta V_{\text {void }}=V_{\text {void }}^{598 K}-V_{\text {void }}^{298 K}$ is $\sim 10 \AA^{3}$. 


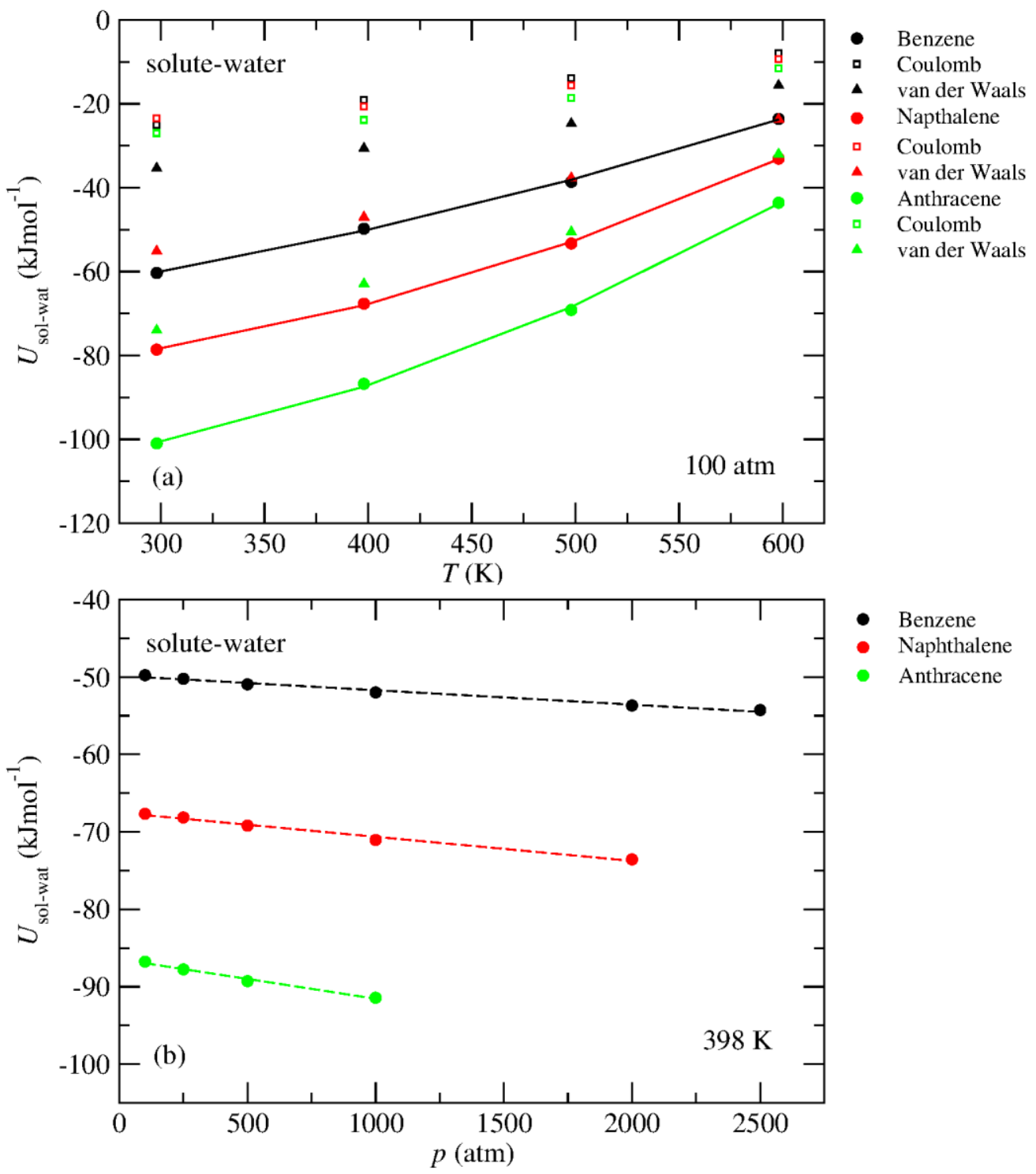

Figure 4-SI - (a) Temperature and (b) pressure dependence of the solute-water non-bonded potential energy for benzene, naphthalene, and anthracene aqueous solutions at 100 atm and $398 \mathrm{~K}$, respectively. The shortrange $(10 \AA)$ van der Waals and Coulombic components of the potential energy are shown as a function of temperature. 

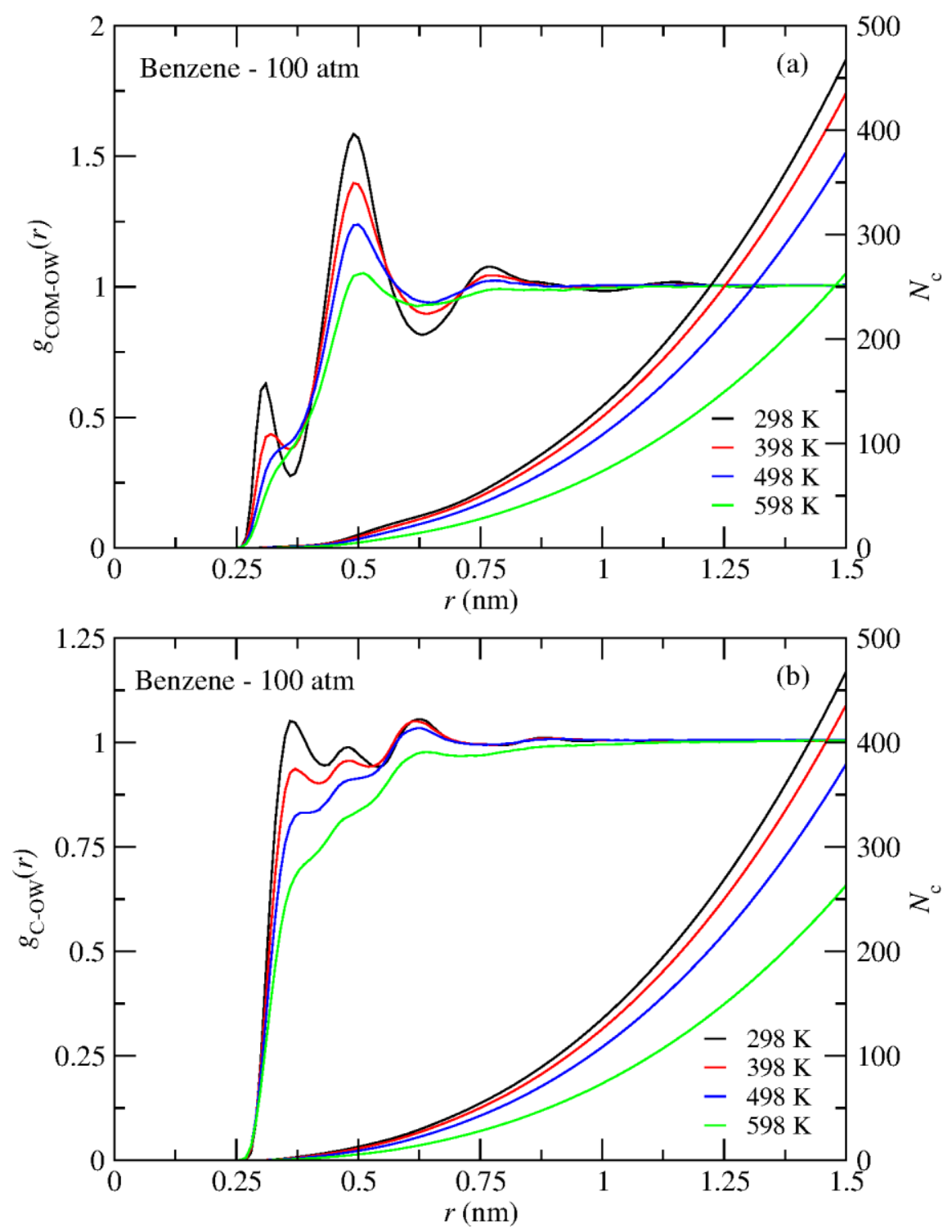

Figure 5-SI - Benzene-water oxygen radial distribution functions, $g(r)$, and coordination number $\left(N_{\mathrm{c}}\right)$ at 100 atm and temperatures between $298 \mathrm{~K}$ and $598 \mathrm{~K}$. (a) benzene centre of mass - oxygen (COM-OW) rdf and (b) benzene carbon-oxygen (C-OW) rdf. The first peak of the COM-OW rdf, more visible at $298 \mathrm{~K}$, corresponds to $\sim 1.5$ hydrogen bonds formed between water and the aromatic ring. The radial distributions functions at $298 \mathrm{~K}$ and $1 \mathrm{~atm}$ are almost identical and are not shown. 

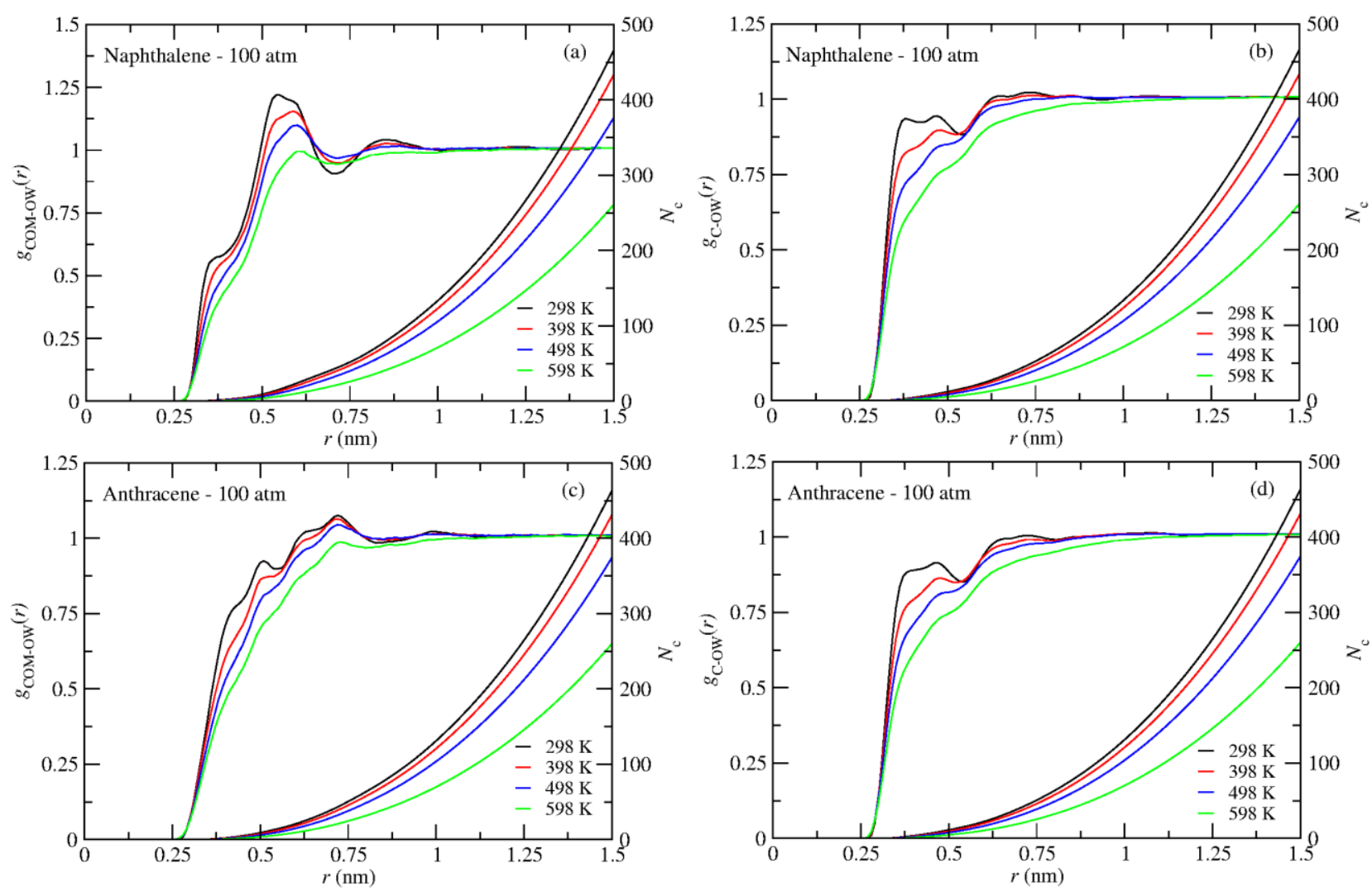

Fig. 6-SI - Naphthalene and anthracene COM-OW and C-OW rdfs and the respective coordination numbers at $298 \mathrm{~K}, 398 \mathrm{~K}, 498 \mathrm{~K}$, and $598 \mathrm{~K}$ and $100 \mathrm{~atm}$. 

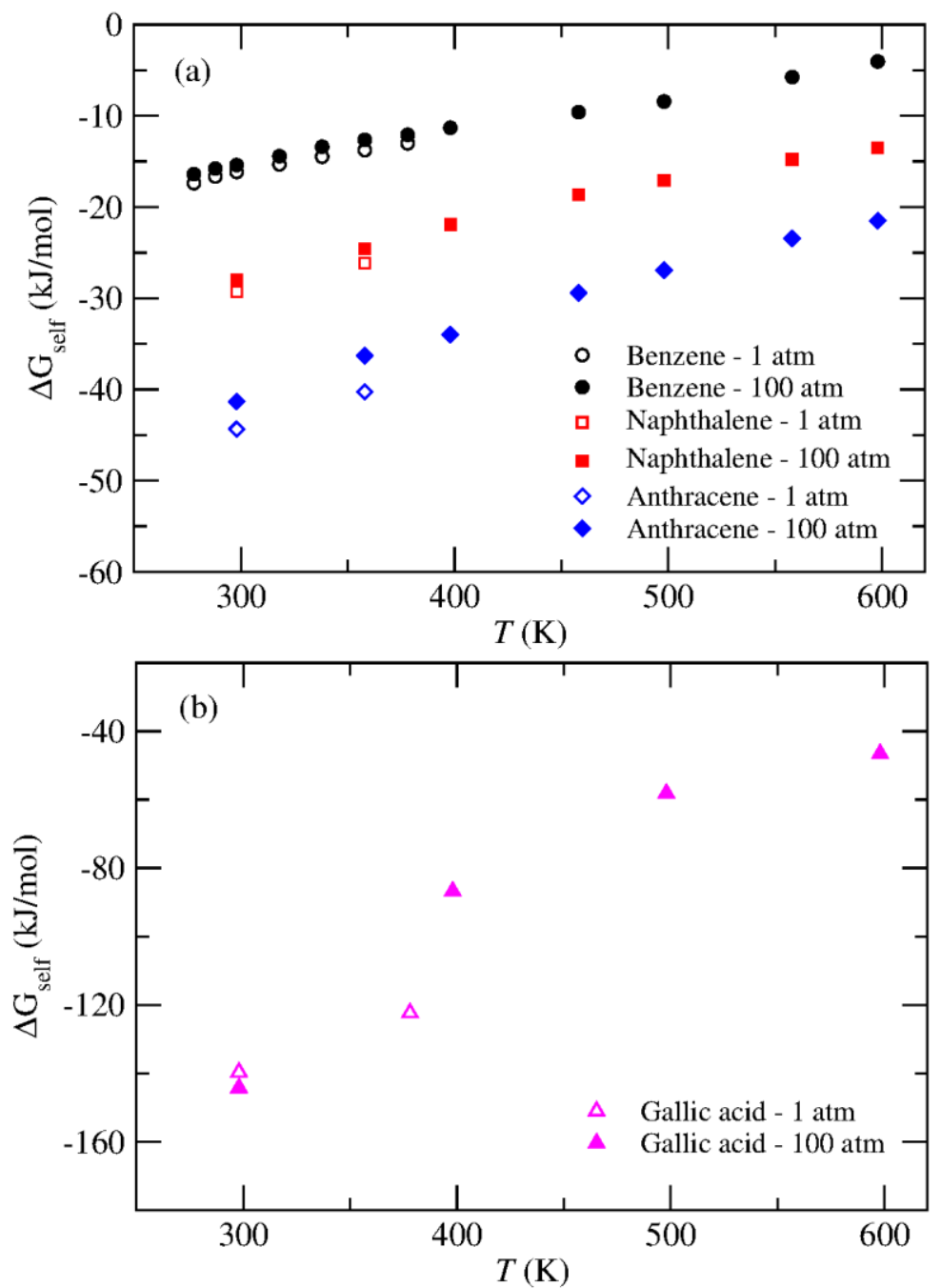

Figure 7-SI - Temperature dependence of the self-free energies for pure (a) benzene, naphthalene, and anthracene, and (b) gallic acid, at $1 \mathrm{~atm}$ and $100 \mathrm{~atm}$. 

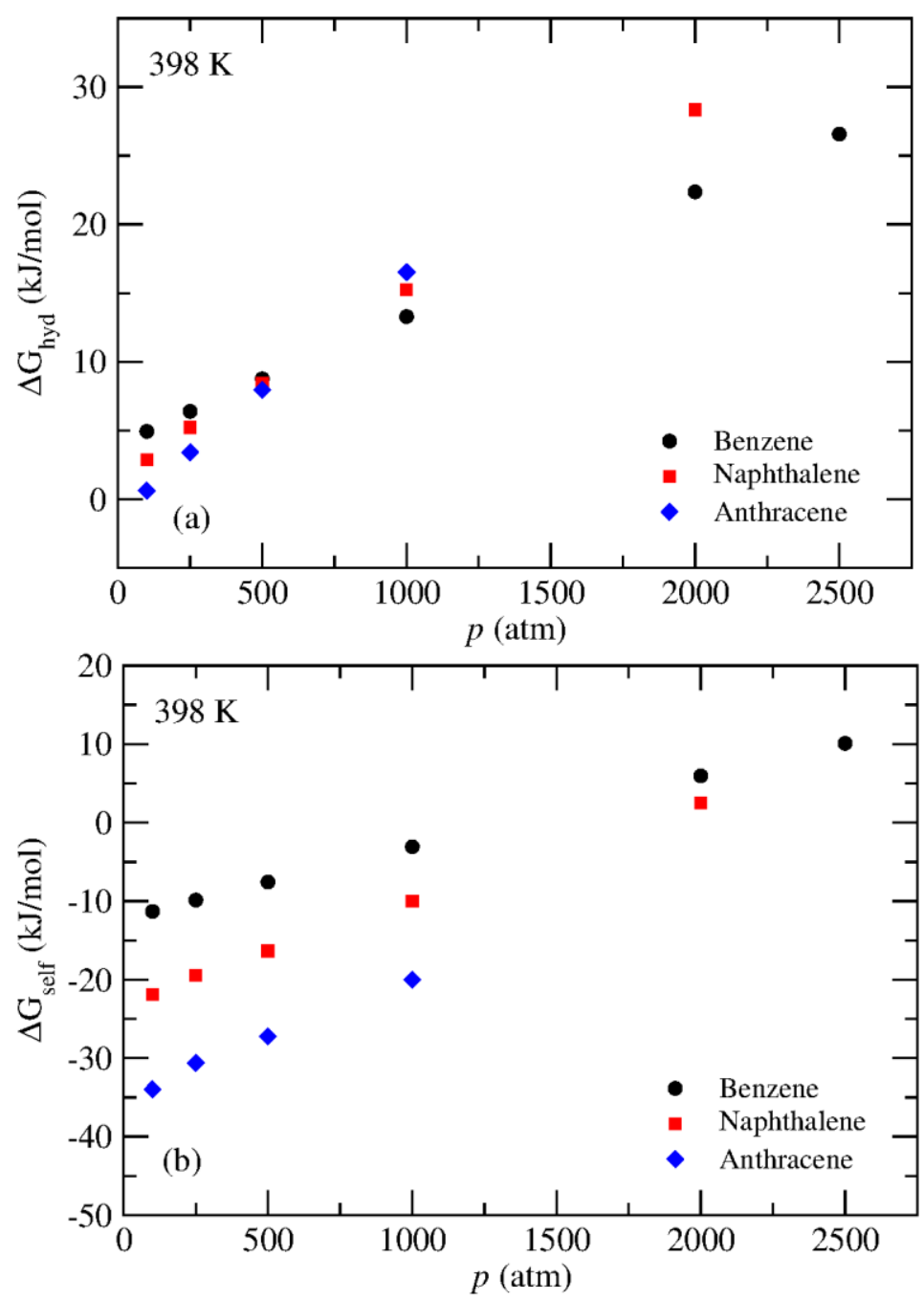

Figure 8-SI - Pressure dependence of the (a) hydration and (b) self-free energies of benzene naphthalene, and anthracene at $398 \mathrm{~K}$. 

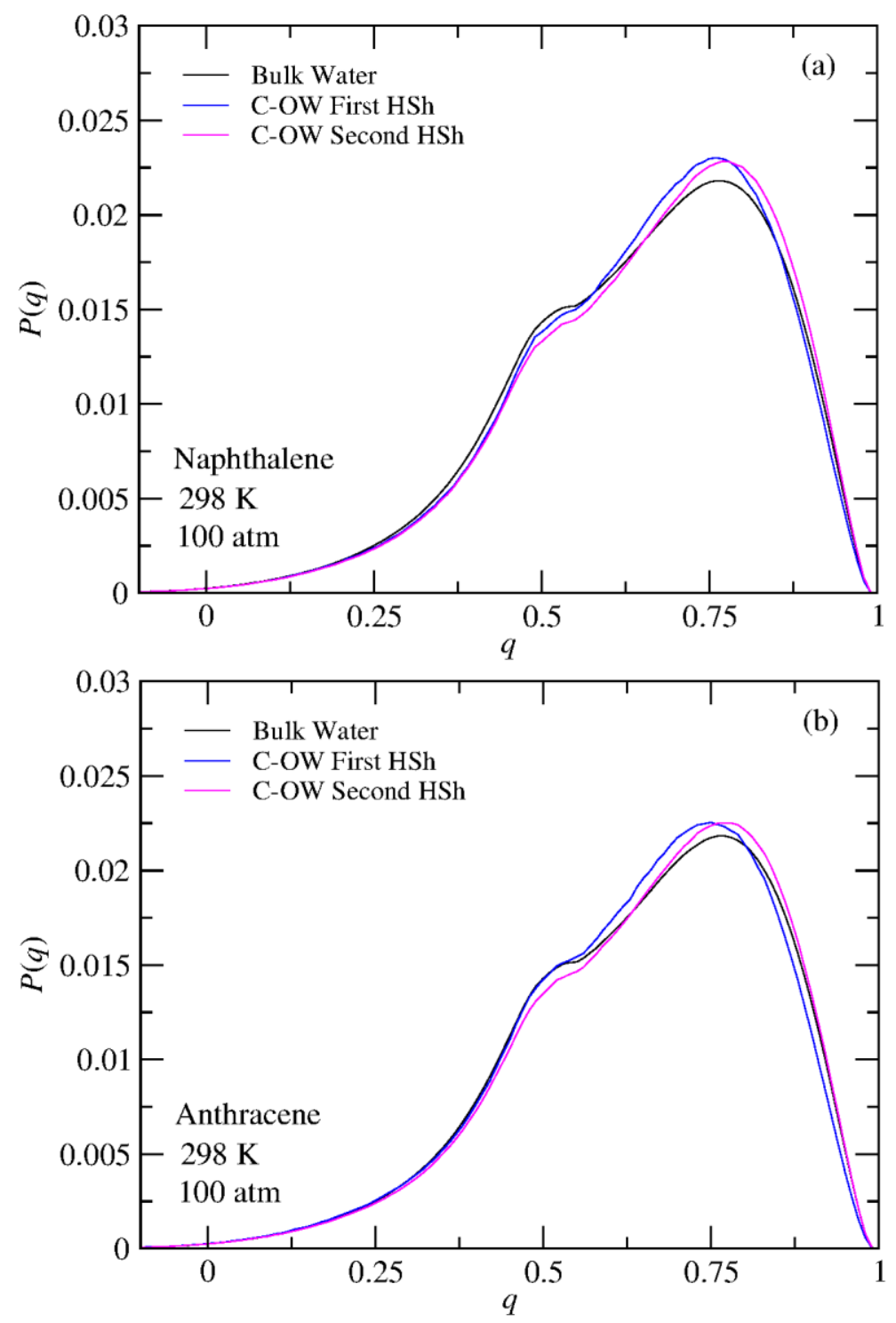

Figure 9-SI - (a) Tetrahedrality, $q$, of bulk water and water molecules with 4 or more water neighbors (4MWN) in the first and second hydration shells (HSh) of the $\mathrm{C}$ atoms of naphthalene and anthracene at 298 $\mathrm{K}$ and $100 \mathrm{~atm}$. Water molecules in the HSh of more than one $\mathrm{C}$ atom are only counted once in the calculation of $q$. The $4 \mathrm{MWN}$ population represents $46 \%$ of the first HSh $\left(N_{\mathrm{w}}=21.9\right.$ and $N_{\mathrm{w}}=26.7$, respectively) and $67 \%$ of the second Hsh ( $N_{\mathrm{w}}=39.7$ and $N_{\mathrm{w}}=47.1$, respectively) for both solutes. $N_{\mathrm{w}}$ is the number of distinct water molecules in the first and second HSh of the $\mathrm{C}$ atoms of naphthalene and anthracene and should not be confused with the coordination numbers, $N_{\mathrm{c}}$. 

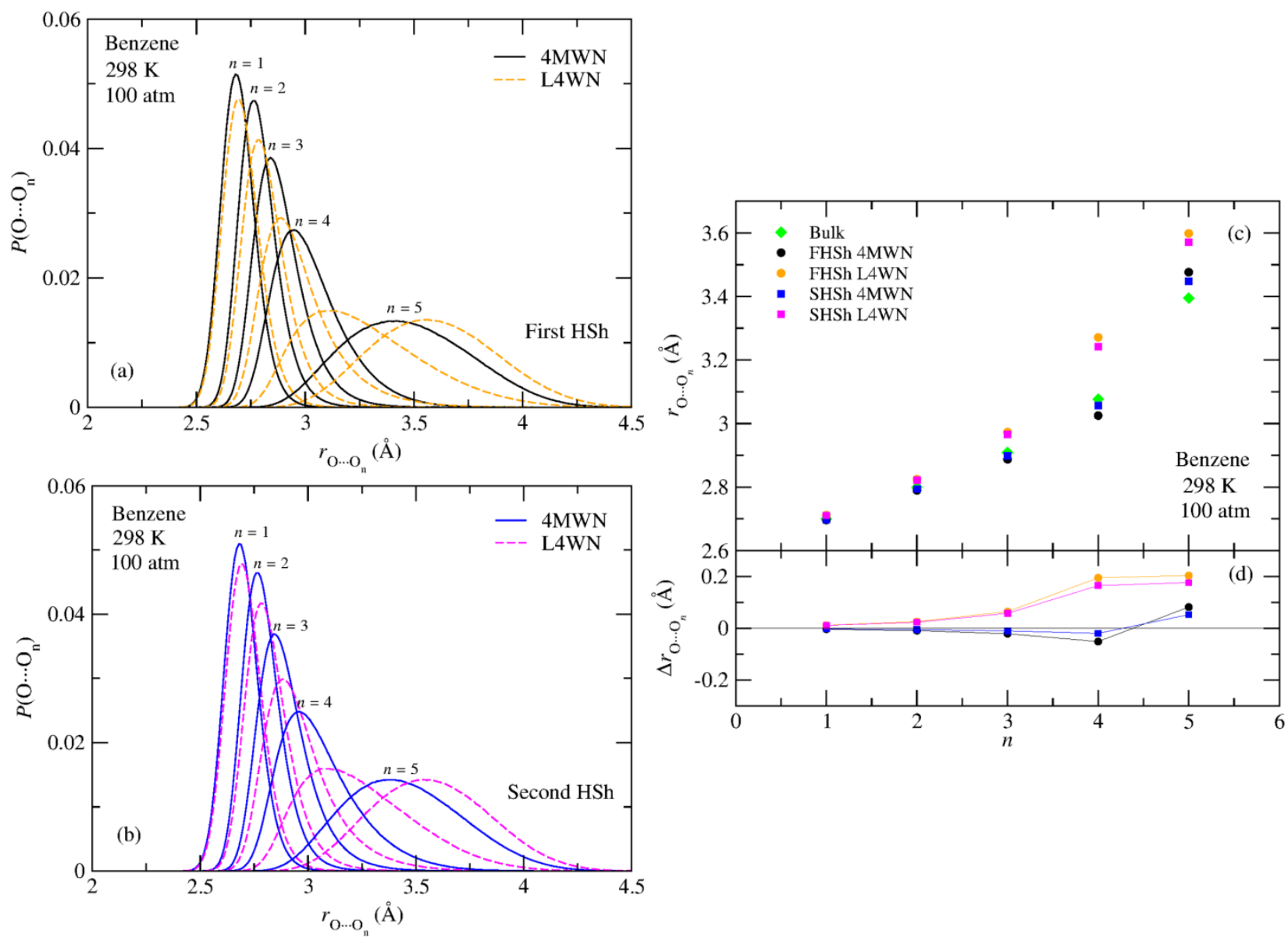

Figure 10-SI - $\mathrm{P}\left(\mathrm{O} \cdots \mathrm{O}_{\mathrm{n}}\right)$ distributions for a benzene aqueous solution at $298 \mathrm{~K}$ and $100 \mathrm{~atm}$. (a) $\mathrm{P}\left(\mathrm{O} \cdots \mathrm{O}_{\mathrm{n}}\right)$ $(\mathrm{n}=1$ to 5 ) for water molecules with 4 or more water neighbors (4MWN) and less than 4 water neighbors (L4WN) in the first (C-OW) HSh, (b) $\mathrm{P}\left(\mathrm{O} \cdots \mathrm{O}_{\mathrm{n}}\right)$ ( $\mathrm{n}=1$ to 5) for water molecules with $4 \mathrm{MWN}$ and $\mathrm{L} 4 \mathrm{WN}$ in the second (C-OW) HSh, (c) average $r_{\mathrm{O} \ldots \mathrm{O}_{n}}$ for the bulk, first, and second HSh, (d) difference between $r_{\mathrm{O} \cdots \mathrm{O}_{n}}$ in the shells and bulk. 

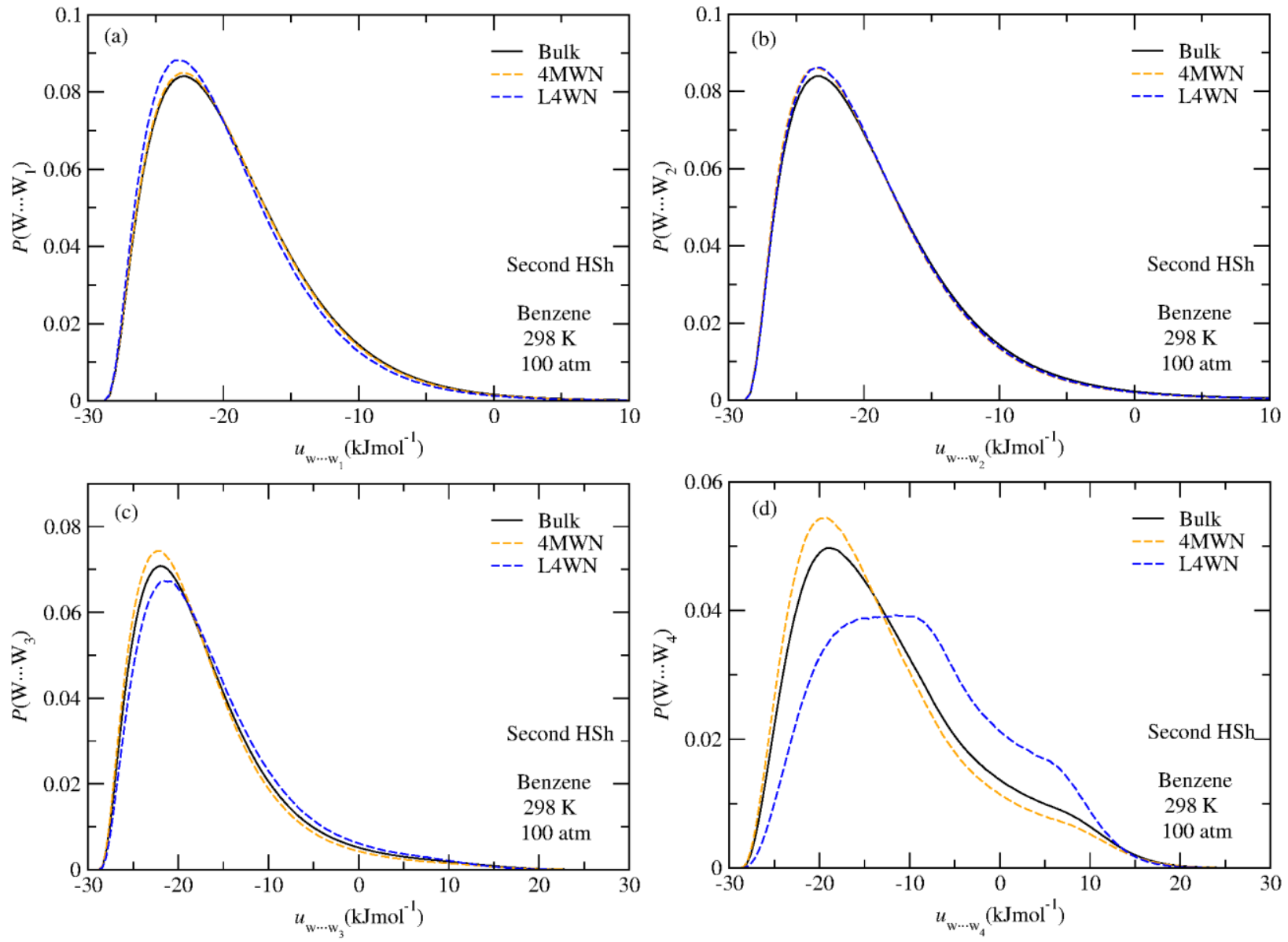

Figure 11-SI - Water pair interaction energy distributions, $P\left(\mathrm{~W} \cdots \mathrm{W}_{\mathrm{n}}\right)$ for $\mathrm{n}=1$ to 4 , for bulk water and water with 4MWN and L4WN in the second hydration shell of benzene at $298 \mathrm{~K}$ and $100 \mathrm{~atm}$. The $N_{\mathrm{W}}$ with $4 \mathrm{MWN}$ and with L4WN is 22.2 and 8.5 , respectively. Similar results were found for an aqueous solution at 1 atm; see Table 2-SI to 5-SI. The distributions for the 4MWN and L4WN in (b) are nearly indistinguishable. 

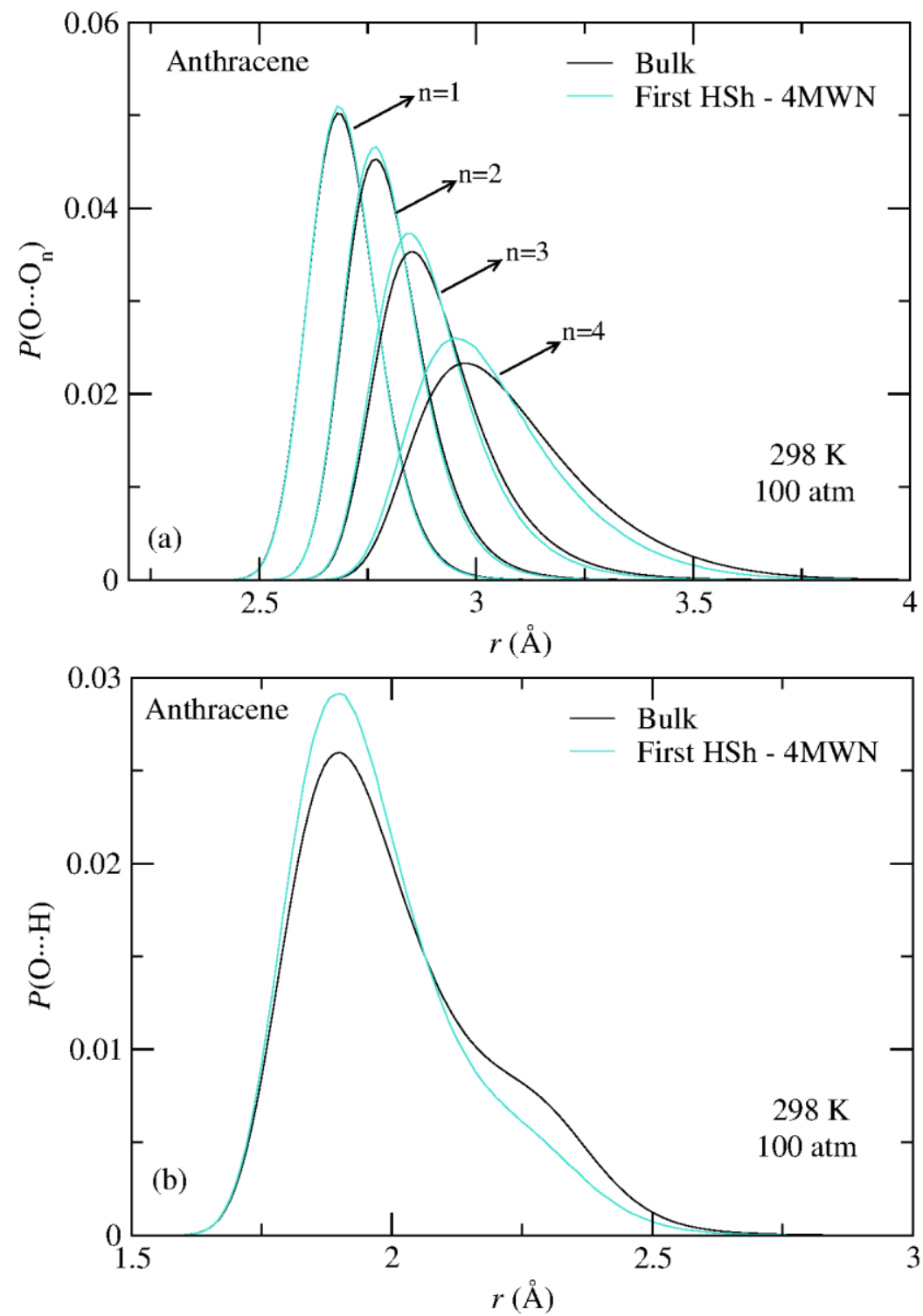

Figure 12-SI - (a) $\mathrm{P}\left(\mathrm{O} \cdots \mathrm{O}_{\mathrm{n}}\right)$ and (b) $\mathrm{P}(\mathrm{O} \cdots \mathrm{H})$ distributions for an anthracene aqueous solution at $298 \mathrm{~K}$ and 100 atm. (a) $\mathrm{P}\left(\mathrm{O} \cdots \mathrm{O}_{\mathrm{n}}\right)(\mathrm{n}=1$ to 4$)$ and (b) $\mathrm{P}(\mathrm{O} \cdots \mathrm{H})$, for the bulk and water molecules with 4 or more water neighbors $(4 \mathrm{MWN})$ in the first (C-OW) HSh. 

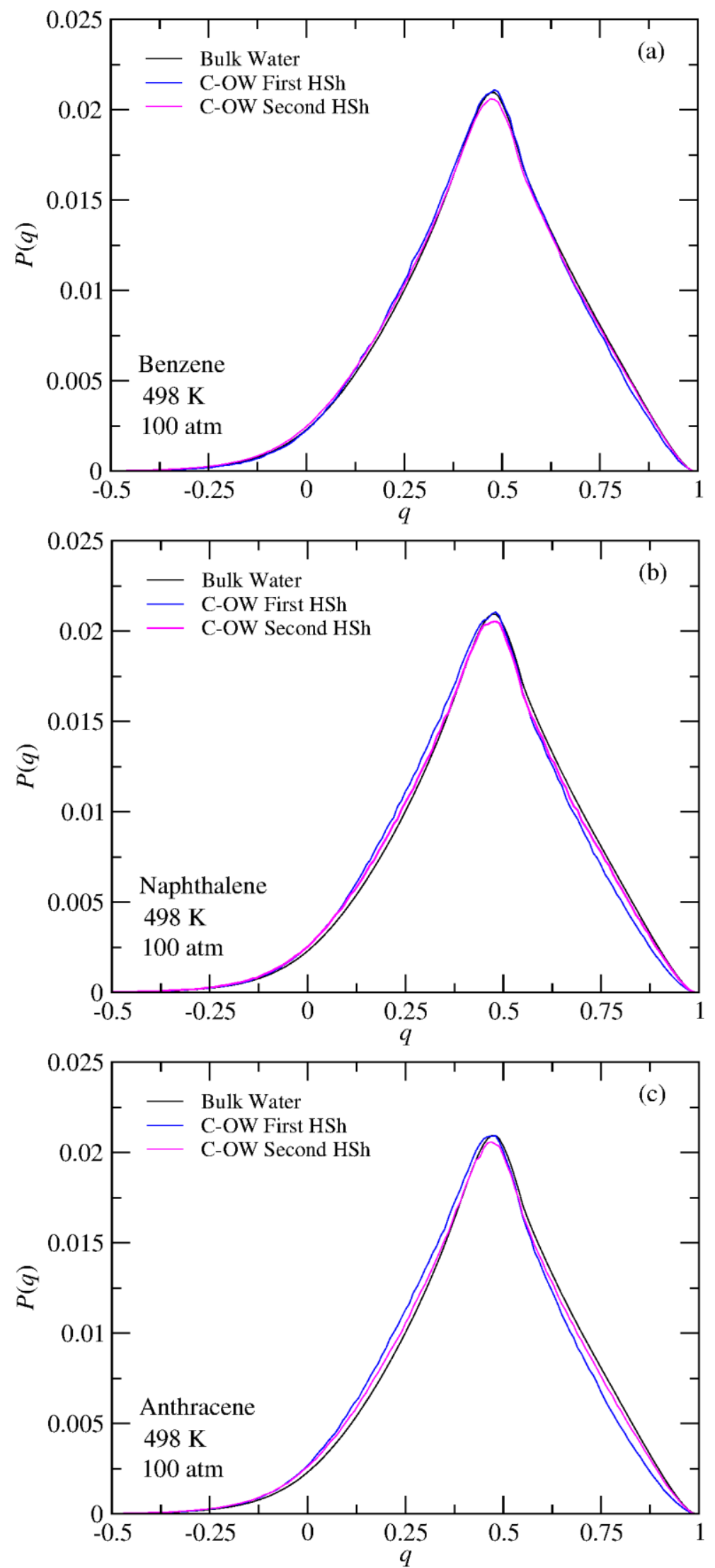

Figure 13-SI - (a) Tetrahedrality, $q$, of bulk water and water molecules with 4 or more water neighbors (4MWN) in the first and second hydration shells of the $\mathrm{C}$ atoms of (a) benzene, (b) naphthalene, and (c) anthracene, at $498 \mathrm{~K}$ and $100 \mathrm{~atm}$. 

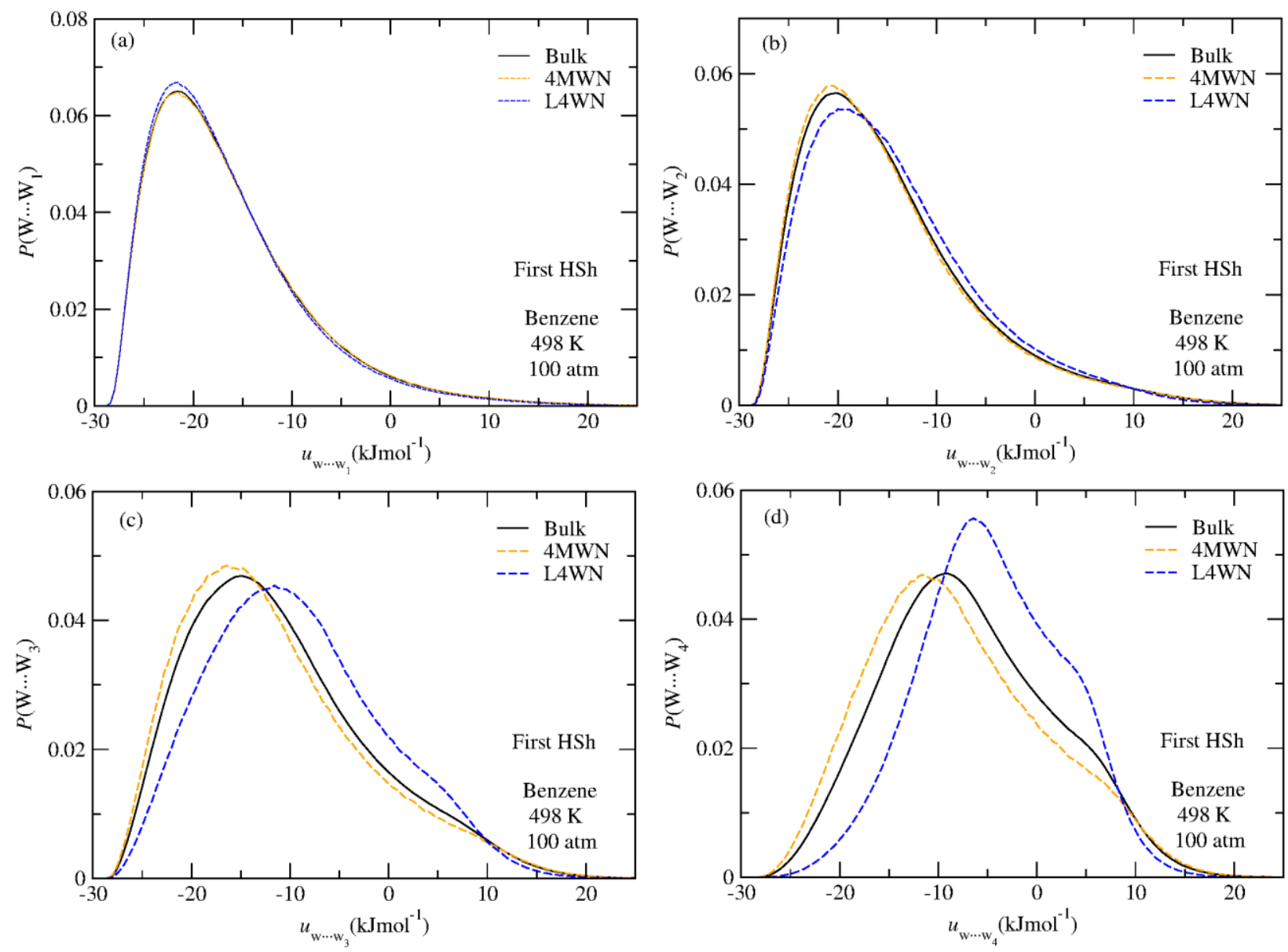

Figure 14-SI - Water pair interaction energy distributions, $P\left(\mathrm{~W} \cdots \mathrm{W}_{\mathrm{n}}\right)$ for $\mathrm{n}=1$ to 4 , for bulk water and water molecules with $4 \mathrm{MWN}$ and L4WN in the first hydration shell of benzene at $298 \mathrm{~K}$ and $100 \mathrm{~atm}$. The $N_{\mathrm{W}}$ with $4 \mathrm{MWN}$ and with $\mathrm{L} 4 \mathrm{WN}$ are 2.6 and 8.4, respectively. 
Table 1-SI - Electrostatic charges (RESP) for the different solutes in the GAFF force field calculated at the $\mathrm{HF} / 6-31 \mathrm{G}^{*}$ level theoretical level.

\begin{tabular}{cccc}
\hline Atom & $q(e)$ & Atom & $q(e)$ \\
\hline Benzene - CH & -0.134163 & Gallic Acid - Ca & -0.419171 \\
Benzene - HC & +0.134163 & Gallic Acid - Cb & +0.309992 \\
Naphthalene - Ca & -0.304487 & Gallic Acid - Cc & -0.087138 \\
Naphthalene - Cb & -0.122841 & Gallic Acid - Cd & +0.178652 \\
Naphthalene - Cc & +0.227105 & Gallic Acid - Ce & +0.841464 \\
Naphthalene - Ha & 0.171046 & Gallic Acid - Oa & -0.483406 \\
Naphthalene - Hb & 0.142729 & Gallic Acid - Ob & -0.593248 \\
Anthracene - Ca & -0.259948 & Gallic Acid - Oc & -0.545195 \\
Anthracene - Cb & -0.130053 & Gallic Acid - Od & -0.634755 \\
Anthracene - Cc & +0.206472 & Gallic Acid - HCa & +0.209448 \\
Anthracene - Cd & -0.442202 & Gallic Acid - HOa & +0.404836 \\
Anthracene - Ha & 0.157876 & Gallic Acid - HOb & +0.453320 \\
Anthracene - Hb & 0.142841 & Gallic Acid - HOd & +0.404857 \\
Anthracene - Hd & 0.207826 & & \\
\hline
\end{tabular}




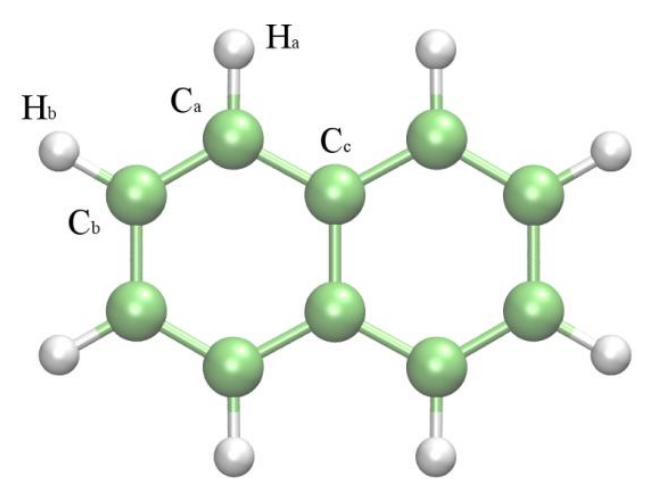

Naphthalene

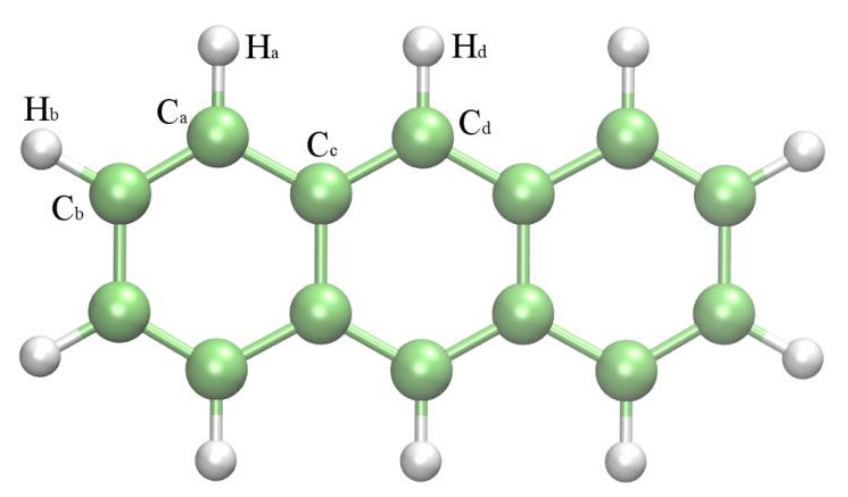

Anthracene

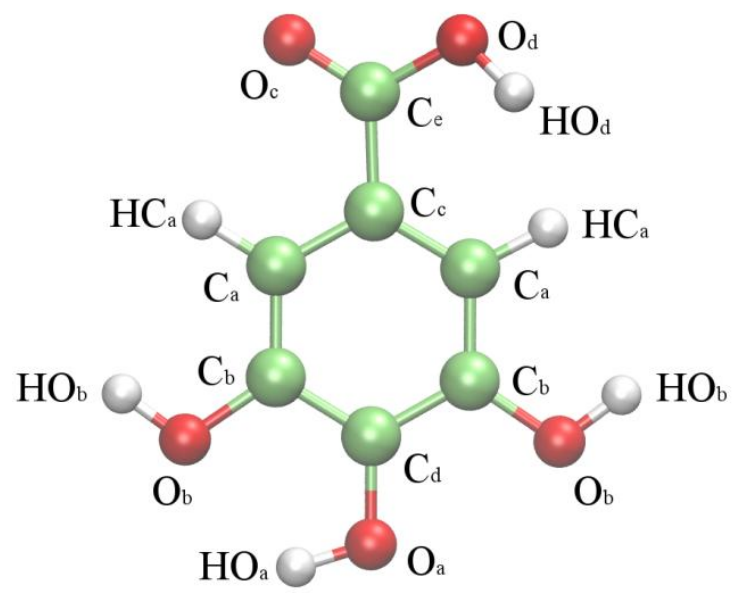

\section{Gallic Acid}

Table 2-SI - Lennard-Jones parameters for the different solutes in the GAFF force field ${ }^{\mathrm{a}}$.

\begin{tabular}{llllll}
\hline Atom & $\sigma(\mathrm{nm})$ & $\varepsilon\left(\mathrm{kJmol}^{-1}\right)$ & System & $\sigma(\mathrm{nm})$ & $\varepsilon\left(\mathrm{kJmol}^{-1}\right)$ \\
\hline Benzene - C & 0.339967 & 0.359824 & Gallic Acid - C & 0.339967 & 0.359824 \\
Benzene - H & 0.259964 & 0.06276 & Gallic Acid - O (= Oc) & 0.295992 & 0.878640 \\
Naphthalene - C & 0.339967 & 0.359824 & Gallic Acid - OH & 0.306647 & 0.880314 \\
Naphthalene - H & 0.259964 & 0.062760 & Gallic acid - H & 0.259964 & 0.062760 \\
Anthracene - C & 0.339967 & 0.359824 & Gallic acid - HO & 0.00000 & 0.00000 \\
Anthracene - H & 0.259964 & 0.06276 & & &
\end{tabular}

${ }^{\mathrm{a}}$ Lennard-Jones parameters are similar for $\mathrm{C}$ and $\mathrm{H}$ atoms for the different solutes; bond lengths, angles, and dihedrals and the respective force constants from GAFF were used and are available from AMBER tools. 
Table 3-SI - Hydration enthalpy of aqueous solutions of benzene at $298 \mathrm{~K}$ and $378 \mathrm{~K}$ and at 1 atm and 100 atm, calculated from the hydration free energy and entropy $\Delta H=\Delta G+T \Delta S$ (Fig. 2) and via eq.(9).

\begin{tabular}{cccc}
\hline$T(\mathrm{~K})$ & $p(\mathrm{~atm})$ & $\Delta H=\Delta G+T \Delta S\left(\mathrm{kJmol}^{-1}\right)$ & $\begin{array}{c}\Delta H \text { eq. }(9) \\
\left(\mathrm{kJmol}^{-1}\right)\end{array}$ \\
\hline 298 & 1 & -34.7 & $-26 .(7) \pm 4^{1}$ \\
298 & 100 & -31.4 & $-25 .(0) \pm 4$ \\
378 & 1 & -13.6 & $-3 .(2) \pm 4$ \\
378 & 100 & -16.1 & $-5 .(3) \pm 3$ \\
\hline
\end{tabular}

${ }^{1}$ Standard deviations calculated through propagation of the $H_{\text {solution, }}, H_{\text {water }}$, and $U_{\text {sol,vacuum }}$ standard deviations calculated from 10 independent trajectories for the aqueous solutions, pure water, and the solute in vacuum. 
Table 4-SI - Water-water nth ( $\mathrm{n}=1$ to 5$)$ average pair interaction energies in the bulk and hydration shells (HSh) of a benzene aqueous solution at $298 \mathrm{~K}$ and $1 \mathrm{~atm}$. First HSh (FHSh); Second HSh (SHSh).

\begin{tabular}{cccccc}
\hline & $\mathrm{n}=1$ & $\mathrm{n}=2$ & $\mathrm{n}=3$ & $\mathrm{n}=4$ & $\mathrm{n}=5$ \\
\hline Bulk & -19.36 & -19.25 & -17.06 & -12.23 & -3.19 \\
FHSh - 4MWN & -19.47 & 19.57 & -17.89 & -14.16 & -2.65 \\
FHSh - L4WN & -19.82 & -19.43 & -16.27 & -8.47 & -2.11 \\
SHSh - 4MWN & -19.48 & -19.53 & -17.65 & -13.31 & -2.87 \\
SHSh - L4WN & -19.81 & -19.45 & -16.39 & -9.00 & -2.17 \\
\hline
\end{tabular}

Table 5-SI - Water-water nth ( $\mathrm{n}=1$ to 5$)$ average pair interaction energies in the bulk and hydration shells (HSh) of a benzene aqueous solution at $298 \mathrm{~K}$ and $100 \mathrm{~atm}$. First HSh (FHSh); Second HSh (SHSh).

\begin{tabular}{cccccc}
\hline & $\mathrm{n}=1$ & $\mathrm{n}=2$ & $\mathrm{n}=3$ & $\mathrm{n}=4$ & $\mathrm{n}=5$ \\
\hline Bulk & -19.34 & -19.23 & -17.04 & -12.21 & -3.21 \\
FHSh - 4MWN & -19.43 & -19.55 & -17.86 & -14.11 & -2.68 \\
FHSh - L4WN & -19.80 & -19.41 & -16.26 & -8.49 & -2.12 \\
SHSh - 4MWN & -19.47 & -19.52 & -17.63 & -13.28 & -2.90 \\
SHSh - L4WN & -19.79 & -19.44 & -16.41 & -9.09 & -2.21 \\
\hline
\end{tabular}

Table 6-SI - Water-water nth ( $\mathrm{n}=1$ to 5 ) average pair interaction energies in the bulk and hydration shells (HSh) of a benzene aqueous solution at $378 \mathrm{~K}$ and $1 \mathrm{~atm}$. First HSh (FHSh); Second HSh (SHSh).

\begin{tabular}{cccccc}
\hline & $\mathrm{n}=1$ & $\mathrm{n}=2$ & $\mathrm{n}=3$ & $\mathrm{n}=4$ & $\mathrm{n}=5$ \\
\hline Bulk & -18.14 & -17.28 & -14.13 & -9.26 & -3.77 \\
FHSh - 4MWN & -18.20 & -17.58 & -14.90 & -10.74 & -3.42 \\
FHSh - L4WN & -18.62 & -17.26 & -12.92 & -6.37 & -2.58 \\
SHSh - 4MWN & -18.29 & -17.58 & -14.63 & -9.92 & -3.58 \\
SHSh - L4WN & -18.63 & -17.32 & -13.04 & -6.50 & -2.64 \\
\hline
\end{tabular}

Table 7-SI - Water-water nth ( $\mathrm{n}=1$ to 5$)$ average pair interaction energies in the bulk and hydration shells (HSh) of a benzene aqueous solution at $378 \mathrm{~K}$ and $100 \mathrm{~atm}$. First HSh (FHSh); Second HSh (SHSh).

\begin{tabular}{cccccc}
\hline & $\mathrm{n}=1$ & $\mathrm{n}=2$ & $\mathrm{n}=3$ & $\mathrm{n}=4$ & $\mathrm{n}=5$ \\
\hline Bulk & -18.11 & -17.26 & -14.14 & -9.28 & -3.79 \\
FHSh - 4MWN & -18.18 & -17.56 & -14.89 & -10.75 & -3.43 \\
FHSh - L4WN & -18.59 & -17.24 & -12.94 & -6.41 & -2.59 \\
SHSh - 4MWN & -18.26 & -17.56 & -14.63 & -9.94 & -3.59 \\
SHSh - L4WN & -18.60 & -17.31 & -13.06 & -6.55 & -2.65 \\
\hline
\end{tabular}

